\title{
How Many People Live with Dementia in Portugal? A Discussion Paper of National Estimates
}

\author{
Manuel Gonçalves-Pereira ${ }^{a}$ Ana Verdelho ${ }^{b, c}$ Matthew Prina ${ }^{d}$ \\ Maria João Marques ${ }^{\mathrm{a}}$ Miguel Xavier ${ }^{\mathrm{a}, \mathrm{e}}$ \\ ${ }^{a}$ Comprehensive Health Research Center, CEDOC, Nova Medical School/Faculdade de Ciências Médicas, \\ Universidade Nova de Lisboa, Lisbon, Portugal; b Neurology Service, Department of Neurosciences and Mental \\ Health, Hospital de Santa Maria, Centro Hospitalar Universitário Lisboa Norte, Lisbon, Portugal; ' Instituto de \\ Medicina Molecular, Instituto de Saúde Ambiental, Faculdade de Medicina, Universidade de Lisboa, Lisbon,

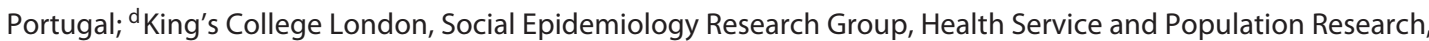 \\ Institute of Psychiatry, Psychology and Neuroscience, London, UK; e National Program for Mental Health, General \\ Directorate of Health, Lisbon, Portugal
}

\section{Keywords}

Dementia · Alzheimer disease - Epidemiology · Populational study · Community · Older people

\begin{abstract}
Dementia poses major public health challenges, and highquality epidemiological data are needed for service planning. Published estimates of numbers of people with dementia in Portugal have been based, in most cases, on prevalence rates derived from international studies or expert consensus. As in many other countries, Portuguese community prevalence studies' results are nongeneralizable to a country level. Moreover, their prevalence estimates differ (not surprisingly, owing to different methodologies, e.g., design, sampling, and diagnostic criteria). Regardless, the Portuguese 10/66 Dementia Research Group (10/66 DRG) population-based survey fulfilled 10 out of 11 Alzheimer's Disease International quality criteria for prevalence studies. It relied on cross-culturally validated methods, fostering a wide comparability of results. Therefore, we can provide rough estimates of 217,549 community dwellers with dementia in Portugal according to the 10/66 DRG criteria (that
\end{abstract}

would be only 85,162 according to DSM-IV criteria). This refers to people aged 65 years or older who are not institutionalized. Although broadly consistent with international projections, these estimates must be cautiously interpreted. Particularly in the context of scarce funding, which will probably last for years, we need more efficient, evidence-based dementia policies. Concerning further epidemiological studies, high-quality methods are needed but also their comparability potential should be improved at national and international levels. Most of all, fund allocation in Portugal should now privilege routine dementia information systems in both health and social services.

(C) 2021 The Author(s). Published by S. Karger AG, Basel on behalf of NOVA National School of Public Health

\section{Quantas pessoas com demência vivem em Portugal?} Uma discussão das estimativas nacionais

Palavras Chave

Demência · Doença de Alzheimer · Epidemiologia • Estudo populacional · Comunidade · Envelhecimento karger@karger.com www.karger.com/pjp

Karger $\stackrel{\text { ' }}{5}$

BOPEN ACCESS (c) 2021 The Author(s). Published by S. Karger AG, Basel on behalf of NOVA National School of Public Health

This is an Open Access article licensed under the Creative Commons Attribution-NonCommercial-4.0 International License (CC BY-NC) (http://www.karger.com/Services/OpenAccessLicense), applicable to the online version of the article only. Usage and distribution for commercial purposes requires written permission.
Correspondence to:

Manuel Gonçalves-Pereira, gpereira@nms.unl.pt 


\section{Resumo}

As demências são um grave problema de saúde pública e os serviços deveriam ser planeados tendo em conta o conhecimento epidemiológico. As estimativas publicadas quanto ao número de pessoas com demência em Portugal têm sido baseadas, maioritariamente, nos resultados internacionais de estudos de prevalência ou consensos de peritos. Os resultados dos estudos de campo portugueses sobre prevalência das demências diferem (o que não é surpreendente, dadas as discrepâncias metodológicas em termos de desenho, amostragem ou critérios diagnósticos). Tal como em muitos outros países, estes resultados não são generalizáveis a nível nacional. Todavia, o estudo populacional realizado em Portugal com a metodologia do '10/66 Dementia Research Group' (10/66 DRG) alcançou um número elevado de critérios de qualidade ADI - Alzheimer's Disease International para estudos de prevalência (10 em 11). Como se baseou em métodos validados transculturamente, os seus resultados prestam-se a comparações internacionais. Permitem estimar em cerca de 217,549 as pessoas mais velhas com demência, residindo na comunidade, em Portugal (pelo algoritmo de diagnóstico 10/66 DRG), embora apenas 85,162 pelos critérios DSM-IV. Sendo genericamente concordantes com dados internacionais, estas projecções circunscrevem-se a pessoas não institucionalizadas e devem ser interpretadas prudentemente. Sobretudo perante constrangimentos financeiros globais e previsivelmente duradouros, também na área da demência se impõem políticas com base científica e eficientes. Futuros estudos epidemiológicos deveriam assegurar, a par da qualidade metodológica, a comparabilidade de resultados, a nível nacional e internacional. Nos tempos mais próximos, defendemos o foco na melhoria dos sistemas de informação sobre demência em Portugal, ao nível dos serviços de saúde e sociais.

(c) 2021 The Author(s). Published by S. Karger AG, Basel on behalf of NOVA National School of Public Health

\section{Service Planning Should Rely on Epidemiological Evidence}

Dementia is a public health issue worldwide, with a heavy burden of disease and impact on families and informal caregivers [1-3]. In Portugal, official policies have been lacking for decades $[4,5]$, but efforts were recently made toward a national dementia strategy $[6,7]$.

Efficient dementia prevention and care delivery call for the implementation of an integrated health and social services framework. A robust evidence base is needed [5], and international reports advise regular updating of epi-

Counts of People with Dementia in

Portugal: A Discussion of Estimates demiological data $[1,8]$. Recently, high-quality research was conducted in low- and middle-income countries [9], whereas in more industrialized regions, where most classic prevalence studies have taken place, we run the risk of becoming outdated. In Europe, epidemiological surveys are nowadays difficult to implement, owing to financial constraints and low participation. This applies not only to costly incidence studies but also to prevalence ones.

Although epidemiological fieldwork studies were inexistent in Portugal until recently, important evidence on the community prevalence of dementia is now available. Regardless, 2 issues remain. First, published Portuguese estimates of numbers of people with dementia have not considered evidence directly stemming from populational fieldwork. Second, should we use findings derived from national samples to estimate those numbers, the results of Portuguese community prevalence studies will differ to a considerable extent. The question remains: why do they differ? In this paper, we aim to address these issues, contributing to the discussion of dementia policies and service planning in Portugal. Mild cognitive disorders are beyond our aim despite their importance as a risk factor for dementia in up to a fifth of older-age people and the need for adequate interventions [8]. Instead, we chose to focus on cognitive decline with consequent social or occupational impairment, i.e., dementia.

\section{Published Counts of People with Dementia in Portugal}

Until recently, Portuguese authors were restricted to indirect methods to estimate the number of people with dementia in the Country. These extrapolations relied on international prevalence rates or expert consensus. A first one [10] was published in 1994, based on EURODEM study results; Garcia et al. estimated 92,470 persons in the general population, 48,706 of them with Alzheimer disease $(\mathrm{AD})$. The EuroCODE consortium provided an updated number of 153,000 in 2008 [11] and Alzheimer Europe reported 182,526 people with dementia aged $60+$ years in 2013 [12]. Santana et al. [13] then used the 2005 Delphi consensus rates for the EURO A region [14] to estimate 160,287 people with dementia aged 60 years or older by 2014 , as well as $80,144-112,201$ people with AD. Others [15] calculated 187,052 in 2020, based again on the Global Prevalence of Dementia consensus [14].

Despite their usefulness, there are obvious caveats with such extrapolations. Paraphrasing Ferri et al. [14]: reliability of international consensus estimates does not ensure validity, particularly regarding regions with fewer popula- 
Table 1. Three studies on the prevalence of dementia in Portuguese samples: main characteristics and results

\begin{tabular}{|c|c|c|c|}
\hline Study & Nunes et al. [16] & The 10/66 DRG study [17] & Ruano et al. [18] \\
\hline Geographical area & $\begin{array}{l}\text { Urban (S.J. Madeira) } \\
\text { and rural (Arouca) }\end{array}$ & $\begin{array}{l}\text { Urban (Fernão Ferro, Seixal) } \\
\text { and rural (Mora, Évora) }\end{array}$ & Urban (Oporto) \\
\hline Sampling & $\begin{array}{l}\text { Random from health } \\
\text { center registries }\end{array}$ & $\begin{array}{l}\text { Population-based (all old-age } \\
\text { people in the catchment areas) }\end{array}$ & $\begin{array}{l}\text { Population-based } \\
\text { (representative of Oporto) }\end{array}$ \\
\hline Age of the participants, years & $55-79$ & $\geq 65$ & $\geq 55$ \\
\hline $\begin{array}{l}\text { Valid clinical diagnoses of depression/ } \\
\text { anxiety? }\end{array}$ & No (GDS-brief version) & Yes (GMS-AGECAT) & No (BDI) \\
\hline Diagnostic criteria for dementia & DSM-IV TR & DSM-IV and 10/66 DRG & DSM-V \\
\hline
\end{tabular}

GDS, Geriatric Depression Scale; BDI, Beck Depression Inventory. ${ }^{a}$ The authors also reported a 1.3\% age-standardized prevalence when using both of the standard populations of Oporto and Portugal.

tional studies and even if they have originated in countries with sociocultural similarities. None of these calculations built on Portuguese fieldwork, and the inclusion or not of nursing home $(\mathrm{NH})$ residents was not entirely clear. Now that community prevalence studies - their own limitations notwithstanding - are available, an update is needed.

In fact, a 2019 policy report by Alzheimer Europe estimated the total number of people with dementia in Europe and additionally extrapolated per country. Regarding Portugal, this report differed from those mentioned above in that it used raw data combined from studies of national samples [16-18]; 193,516 people living with dementia in the community were estimated [19]. However, the authors did not meta-analyze the national results and it should be highlighted that the 3 studies considered are different in nature (Table 1); pooling their results to produce a single count might oversimplify complex matters. That is why we would now like to discuss the rationale for using our results alone [17] to produce another estimate.

\section{Portuguese Population-Based Studies Yield Different Prevalence Estimates}

Population-based prevalence direct estimates of dementia are available for selected catchment areas in Portugal (Table 1).
The first study was conducted in the north [16] in 2 samples (urban and rural). The prevalence of dementia was calculated according to the Diagnostic and Statistical Manual of Mental Disorders (DSM)-IV criteria [20] and was $2.7 \%$ (95\% CI 1.9-3.8). A second field survey was conducted by our group in the south, also in 2 samples (urban and rural) but using the 10/66 Dementia Research Group (DRG) method [17, 21]. The 10/66 DRG is an international consortium, based at King's College London, whose protocols provide different outputs in terms of dementia case definition not only according to DSM-IV criteria but also according to a regression equation developed in the 10/66 DRG studies [22]. Concerning the prevalence of DSM-IV dementia, the confidence intervals overlapped with the study of Nunes et al. [16], i.e., 3.7\% (95\% CI 3.0-5.0). However, the prevalence according to the 10/66 algorithm was higher, i.e., 9.2\% (95\% CI 7.810.9) [17]. A third survey was conducted in Oporto and reported a $1.3 \%$ estimate for DSM-V dementia prevalence [18].

Besides discrepancies concerning the proportion of dementia subtypes (Table 1), the 3 prevalence estimates are different (especially regarding the results of Ruano et al. [18], even allowing for their use of the most recent DSM version). An obvious question ensues, i.e., what is the explanation for these differences?
60

Port J Public Health 2021;39:58-67 DOI: $10.1159 / 000516503$
Gonçalves-Pereira/Verdelho/Prina/ Marques/Xavier 
Table 2. Three studies on the prevalence of dementia in Portuguese samples: methodological differences according to ADI 2009 criteria

\begin{tabular}{|c|c|c|c|}
\hline ADI criteria ${ }^{a}$ & $\begin{array}{l}\text { Nunes et al. } \\
{[16]}\end{array}$ & $\begin{array}{l}\text { The } 10 / 66 \\
\text { DRG study } \\
{[17]}\end{array}$ & $\begin{array}{l}\text { Ruano et al. } \\
\text { [18] }\end{array}$ \\
\hline \multicolumn{4}{|l|}{ Sample size $(n)$} \\
\hline \multicolumn{4}{|l|}{$<500$} \\
\hline $500-1,499$ & 1,146 & 1,405 & 730 \\
\hline \multicolumn{4}{|l|}{$1,500-2,999$} \\
\hline 2-phase study with no sampling of screen negatives & Yes & & Yes \\
\hline 2-phase study, with sampling of screen negatives but no weighting back & & & \\
\hline 1-phase or 2-phase study with appropriate sampling and weighting & & Yes & \\
\hline \multicolumn{4}{|l|}{ Response proportion, \% } \\
\hline$<60$ & 52.6 & & \\
\hline Formal disability assessment & Yes & Yes & No \\
\hline Informant interview & Yes & Yes & Yes \\
\hline Clinical interview & Yes & Yes & Yes \\
\hline
\end{tabular}

Values are presented as numbers unless otherwise stated. ${ }^{a}$ An overall quality score ( $0-11$ points) derived by summing scores for the following elements: sample size $(<500=0.5$ points; $500-1,499=1$ point; $1,500-2,999=1.5$ points; and $>2,999=2$ points); design ( 2 -phase study with no sampling of screen negatives $=0$ points; 2 -phase study with sampling of screen negatives but no weighing back $=1$ point; and 1-phase study or 2-phase study with appropriate sampling and weighing $=2)$; response proportion $(<60 \%=1$ point; $60-79 \%=2$ points; and, $>79 \%=3$ ); and diagnostic assessment (inclusion of a multidomain test battery, a formal disability assessment, an informant interview, and a clinical interview $=1$ point each).

\section{Comparing the Methods of Portuguese Prevalence Studies}

In Table 2, we display additional characteristics (strengths and limitations) of the 3 studies, following the Alzheimer's Disease International (ADI) quality criteria for prevalence studies [23] frequently adopted in reviews and meta-analyses $[1,24]$.

Our study used the 10/66 DRG method. In the last 2 decades, this consortium generated high-quality evidence on the epidemiology not only of dementia but also of mental health, non-communicable diseases, disability, and care dependences [9]. The protocols for prevalence surveys were used in many countries (mainly but not only low- and middle-oncome countries), impacting on research and public health policies worldwide [9].

As detailed elsewhere [17], there were several reasons for implementing the 10/66 DRG method in Portugal. First, following international recommendations $[1,25]$, we wanted a fixed and fully structured 1-stage, catchment area survey, facilitating international comparisons and reassessments over time. Despite the economic advantag- es of classical double-phase designs, 1-phase approaches are strongly recommended; there is no attrition bias/informative censoring or need to control for false negatives during screening $[1,26]$. Second, we were interested in comprehensive assessments directed not only at cognitive impairment. Psychiatric disorders are crucial for differential diagnosis and their presence may bias estimates of dementia-associated disability and burden of disease. Late-life depression, in particular, has complex relations to dementia; it may be reactive, "homophenotypic", a prodrome, or a risk factor for dementia, or it may just coincide $[27,28]$. In this area, we should not rely on brief rating scales uncritically, especially when cut-off validity cannot be taken for granted [29]. Standardized 10/66 DRG assessments, on the contrary, include, for example, an extensive cognitive module, physical examinations, detailed informant interviews, and the geriatric mental state-automated geriatric examination for computer assisted taxonomy (GMS-AGECAT; a semi-structured interview which is the gold standard in old-age psychiatry epidemiological research) [30]. Altogether, the protocol provides evidence on dementia diagnoses (DSM-IV, 
Table 3. Number of people with dementia in Portugal according to $10 / 66$ DRG survey prevalence estimates

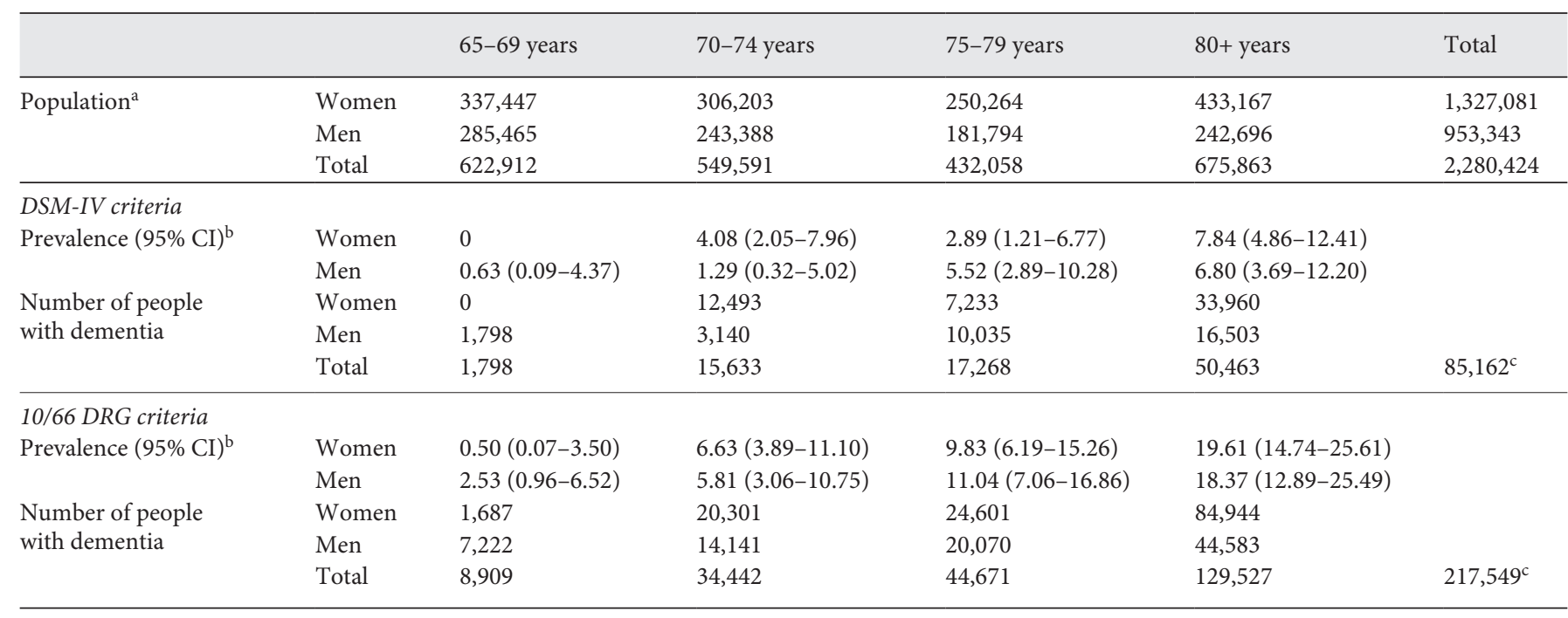

${ }^{a}$ Latest annual resident population estimates: 2019, from the INE (2020) - https://www.ine.pt/xportal/xmain?xpid=INE\&xpgid=ine_indicadores\&ind OcorrCod $=0008273 \& x$ lang $=$ en. ${ }^{b}$ Prevalence estimates from the first 10/66 DRG survey in Portugal [17]. ${ }^{c}$ This total is based on the sum of age and sex specific estimates.

ICD-10, and 10/66) and subtypes, mental disorders ("organicity" - including dementia - depression, anxiety, and psychosis), self-reported health conditions and risk factors, disability/functioning (WHODAS 2.0), and service use. Eventually, we were able to assess late-life depression (ICD-10 and subsyndromal depression) [31]. Finally, we wanted to address concerns that DSM criteria may systematically underestimate the true dementia prevalence in low-education, low-awareness settings. The proportion of old-age people in Portugal is now around 20\%, and their illiteracy rate is still high [17]. The 10/66 DRG protocol compares DSM-IV caseness against the 10/66 method, which has been proven to be fair in terms of culture and education, in settings not strikingly different from Portuguese rural communities. We acknowledge lacking conclusive evidence of the relative validity of the DSM and 10/66 DRG approaches in Europe, and the current pandemic is delaying our aim of directly establishing the validity of the 10/66 DRG criterion. However, the 10/66 diagnostic algorithm has been extensively validated worldwide [9], and our findings support the concurrent validation of 10/66 and DSM-IV diagnoses [17].

Therefore, we assessed all individuals aged 65 years or older who were residents of mapped catchment areas chosen to reflect nationally typical scenarios [17, 21]. Given the method (design, sampling, and assessment type), the response rate $(82 \%)$, and the analyzable sample size $(n=1,405)$, the overall ADI quality score [23] for the study was 10 out of 11 (Table 2). Despite their own limitations [17], these findings provide a better picture of the Portuguese reality than estimates based on studies conducted abroad, seldom on nationally representative samples themselves [32]. Concerning dementia subtypes, $41.9 \%$ of the 10/66 DRG cases were diagnosed with AD and $30.2 \%$ could not be allocated to pure subtypes [17]. Findings were broadly consistent with pooled estimates of the AD prevalence in Europe (5.05\%; 95\% CI $4.73-$ 5.39) [33].

The studies of Nunes et al. [16] and Ruano et al. [18] were similar in that they adopted classical 2-phase designs (a screening with cognitive tests followed by detailed clinical assessments of participants screening positive, i.e., probable cases). Both relied on the clinical expertise of clinicians in the second phase; none reassessed a random sample of participants screening negative in the first phase, thereby increasing the probability of "false negatives" and making it impossible to weigh back final results $[1,34]$. As ours, their results were not generalizable beyond areas under study and did not target $\mathrm{NH}$, as discussed below. Discrepancies in dementia subtype prevalence estimates are evident, but we would rather focus on dementia syndrome diagnosis, as it is more important for burden of disease evaluation and service planning.

Although the 3 Portuguese studies' results are not directly comparable, they all contribute to our understanding of dementia epidemiology in Portugal, provided their
Gonçalves-Pereira/Verdelho/Prina/ Marques/Xavier 
results are discussed taking methodological options into account. As the 10/66 DRG study reported 2 alternative diagnoses of dementia, and meets most ADI quality criteria, its prevalence estimates may provide an evidence base for estimates of people with dementia living in the community in Portugal.

\section{Updated Estimates of People with Dementia According to 10/66 DRG Results}

Overall, the 10/66 DRG study raises important questions regarding policies and services. Which diagnostic criteria are more appropriate to reflect the community burden of dementia: "classical" DSM ones or those of the "epidemiological" and clinically validated 10/66? Moreover, if we were to rely on the latter, how would this shape our estimates of numbers of older people with dementia in Portugal today? Let us start with the second question and take the first one when discussing those numbers.

Estimates regarding Numbers of Community Dwellers with Dementia in Portugal

We replicated the method of Santana et al. [13] but used age and sex specific prevalence estimates from the 10/66 DRG study [17] to update numbers for the Portuguese older people population in 2019 (2,280,424 residents), as retrieved from official estimates on June 15, $2020[35,36]$. We did not consider the age interval of 60 64 years, as this category had not been included in our field survey. We considered an aggregate age category of 80 years or older, due to small numbers in our study for those in the separate categories $80-84$ and 85 years or older.

Table 3 presents a rough estimation of numbers of noninstitutionalized older-age people with dementia, in Portugal, based on prevalence rates resulting from the 10/66 DRG study (DSM-IV diagnostic criteria vs. the 10/66 DRG algorithm) [17].

\section{Discussion and Limitations}

When we apply the 10/66 DRG dementia prevalence estimate, previous projections in Portugal (160, 287 [13] to 193,516 [19]) and by the GBD 2016 Dementia Collaborators $(166,600$; 95\% CI 139,562-201,560) [3] are exceeded. Our count $(217,549)$ may even underestimate the total number of people with 10/66 dementia as it refers only to community dwellers, specifically aged 65 years or older. It aligns with the 2015 World Alzheimer Report, with me-

Counts of People with Dementia in

Portugal: A Discussion of Estimates ta-analyzed estimates of dementia prevalence by GBD region, where the age-standardized prevalence for those aged 60 years or older was $6.8 \%$ in Western Europe [1]; if people in the age category of 60-64 years had been left out, this would be even closer to our $9.2 \%$ prevalence estimate. Our findings are also in line with the 2017 OECD analysis of international data, estimating Portuguese people with dementia in 20 per 1,000 people in 2017 [37]. The same broadly applies to Alzheimer Europe 2019 estimates of 193,516, although their extrapolation of a prevalence of $1.88 \%$ regards the general population. Santana et al. [13] used the Global Prevalence of Dementia consensus estimates that included institutions [14] and an official number of 210,581 fewer Portuguese people aged 65 years or older in 2014; this influenced their count in different directions, but discrepancies with our results are most likely due to different prevalence estimates as the basis for calculations.

On the other hand, our lower estimate of $85,162 \mathrm{ac}-$ cording to the DSM-IV reopens the debate on which diagnostic framework better conveys the true community burden of dementia, probably undervalued by DSM-IV criteria $[9,38]$. Despite their high reliability, numbers generated based on them probably reflect a narrower proportion of more severe cases, failing to consider numerous cognitively impaired and disabled people who would be typically diagnosed with dementia by clinicians but behave as "false negatives" in surveys. This may be especially so in low- and middle-income countries, rural areas, or low-literacy populations due to difficulties in ascertaining cognitive decline and its consequences [39], further supporting the 10/66 DRG approach $[17,21]$. Of note, a systematic review and meta-analysis reported an age and sex-standardized community prevalence of DSM-IV dementia of $7.1 \%$ in Europe [24]; this is around double of what we found in Portugal [17]. Perhaps the inclusion of our study in the meta-analysis would lower that estimate, probably skewed by some studies restricted to old-old participants [24]. In any case, a single focus on DSM-IV criteria ignores the direction of travel toward current approaches using all available sources of evidence while modeling their potential biasing effects.

We strongly believe that our calculations provide sound evidence-based estimates of considerable numbers of Portuguese community-dwelling people with dementia. The extrapolation builds on fieldwork meeting ADI quality criteria and using structured, transculturally validated methods to foster international comparability. However, this statistical exercise based on a single study 
is not without limitations. First, the current COVID-19 pandemic is having a direct impact on the mortality of older people, including persons with dementia, which is still evolving. Furthermore, we did not include people younger than 65 years of age and used prevalence estimates not generalizable at a national level. Most importantly, these did not include NH residents. Surprisingly, previous Portuguese estimates do not explicitly address this conundrum.

\section{What about People Living in Institutions?}

Gaps in epidemiological evidence regarding NH hinder dementia policy making. The prevalence of dementia in residential care settings changes from country to country, depending on funding, eligibility, cultural values and norms, the availability of family support, and the propensity of women to work outside the home. It may vary from $13.4 \%$ (Hungary) to $70-80 \%$ (Sweden) [40]. However, the Alzheimer Europe Yearbook 2017 did not include this estimate for Portugal, where many people with moderate dementia lack appropriate community services and risk precocious institutionalization. In our survey, we did try to evaluate $\mathrm{NH}$ residents [21] but realized that the low number of people who could be legitimately accessed with appropriate consent would lead to underestimates of the true prevalence. Hence, we decided not to combine them with estimates of participants living in the community [17]. An overview of our findings is available in the online supplementary material (for all online suppl. material see www.karger.com/doi/10.1159/000516503). Regarding other Portuguese studies, Nunes et al. [16] reported residual cases of institutionalized people with cognitive impairment, and Ruano et al. [18] did not include them.

We use the umbrella term $\mathrm{NH}$ as roughly equivalent to the Portuguese ERPI (Estruturas Residenciais para Pessoas Idosas), residential structures for older adults run by nonprofit or for-profit private organizations, sometimes with state funding. They have some nursing staff support and provide higher levels of health and social care than "residential houses", which are rare in Portugal [5]. Though generally nonspecific to people with dementia, most institutional care for older people is provided by them, and some NGO (e.g., Misericórdias) greatly improved their capacity to support frail residents. Around $3.4 \%$ of Portuguese older-age people lived in $\mathrm{NH}$ in 2006 [41], but current estimates are 2,526 ERPI and 99,234 residents in Portugal [42]. These figures do not include nu- merous illegal institutions, probably accounting for around 30.000 residents, or the 4,125 older people supported by the RNCCI (the national integrated continued care network) in long-term and maintenance units in 2019 [43].

Specific estimates of Portuguese $\mathrm{NH}$ residents with dementia are very heterogeneous, ranging from 29 to $78 \%$ [44-48]. The great variability of these findings derives from differences in aims and methodologies (design, sampling, and assessment tools), but they share their limited scope. In summary, the clinical characterization (including estimation of the dementia prevalence) of Portuguese $\mathrm{NH}$ has a long way to go.

\section{What Is Next?}

Debates on trends in the worldwide incidence and prevalence of dementia are ongoing [49]. In high-income countries the incidence may be declining, but evidence is broadly inconsistent regarding changes in prevalence [50, 51]. Regardless, population ageing will probably determine an important increase in numbers of people with dementia $[37,50,52]$ and Portugal is expected to have one of the highest percentages of older people in the world by 2030 [53]. We should beware of optimistic projections regarding this public health problem [50] and focus on efficient dementia care policies $[5,54]$.

\section{Implications for Public Policies}

$\mathrm{WHO}$ and $\mathrm{ADI}$ advocate global responses to dementia as a public health priority $[2,55]$. In Portugal, this requires design and implementation of a true national dementia plan [5,6]. Given concerns about the limited implementation of guidelines and programs/plans [56, 57], priority choice and feasibility of measures are paramount.

We should avoid multiplying separate programs on different old-age health conditions (e.g., diabetes, cardiovascular problems, and dementia) and instead gain focus by integrating them. Regarding primary prevention, for instance, the potential for dementia incidence reduction was calculated for Brazil, Mozambique, and Portugal by reducing risk factors of dementia over time [58]; these included education, vascular risk, and depression [27, 28]. We could benefit from drawing on recent Integrated Care for Older People (ICOPE) guidelines for the management of decline in intrinsic capacity [59]; these recommendations address decline not only in cognition, but also in mobility, nutrition, vision and hearing, and mood
Port J Public Health 2021;39:58-67 DOI: $10.1159 / 000516503$
Gonçalves-Pereira/Verdelho/Prina/ Marques/Xavier 
and continence, aiming to prevent or delay the onset of care dependence and promote healthy ageing. Research, including by the $10 / 66$ DRG, supports this framework [60].

Another key issue involves primary care services. This regards early timely diagnosis of dementia and its appropriate disclosure, as well as areas like treatment monitoring, counselling and support, and monitoring of carers' health [5]. Despite international recommendations on task sharing with neurologists or psychiatrists, coordination and continuity of care in truly collaborative environments is far from being implemented [61].

\section{Implications for Research}

On the other hand, assessment of the situation involves not only epidemiologic but also service delivery assessments and stakeholder mapping [62]. An exercise to define dementia research priorities clarified that no nation can realistically respond alone to such challenges and advised gaining focus to effectively reduce the burden of dementia [63].

In Portugal, we now have community prevalence data and (despite the scarcity of evidence regarding $\mathrm{NH}$ ) the societal burden of dementia is uncontentious. Portuguese health services research has highlighted unmet needs in outpatient clinics [64], problems in access and use of community services [65], and the unavailability of information addressing people with youngonset dementia [66]. However, we lack sustainable, feasible methods to monitor trends in prevalence, incidence (including the conversion of minor neurocognitive disorder to dementia) and survival. The same applies to monitoring of diagnosis, treatment, and general management gaps.

So, what should be done now in Portugal? What research needs should be prioritized and how could they be efficiently met? Given all of the evidence now available, and ongoing work from other Portuguese groups [67], timely repetitions of population-based studies using a fixed methodology in defined catchment areas could be more cost-effective than larger-scale projects. For the moment, however, there is a much greater need for evidence regarding dementia prevalence in $\mathrm{NH}$, case finding in health and social services, and the precise care needs of people with dementia and their families, including earlyonset dementia.

Specifically regarding institutions, there are barriers to conduction of effective research on the true dementia prevalence. Without adequate design and funding, we cannot generate meaningful estimates from a nationally

Counts of People with Dementia in

Portugal: A Discussion of Estimates representative sample of care homes of different types. One additional way to overcome these barriers is to improve the robustness of sampling methods. Low participation due to incapacity to consent when legal representatives are inexistent may be addressed by exceptional ethical and legal approval for epidemiological assessments, on justified grounds.

Characterization of health and social care delivery in dementia is paramount. There is Portuguese research in this area $[65,68-70]$, but improving information systems, e.g., through access to multisectoral data [62], is still overlooked. Meanwhile, to avoid mismatch of resourcing with true needs, one should keep a critical eye on how widely cited estimations of people with dementia are created [32].

\section{Conclusion}

We updated estimates of numbers of community dwellers with dementia in Portugal according to the results of our previous 10/66 DRG survey. These numbers are remarkably higher if we use age and sex specific dementia prevalence estimates according to the 10/66 DRG algorithm. DSM-IV dementia may represent a more specific criterion, restricting the diagnosis to more severe and incontrovertible cases. Both values should be considered cautiously as rough estimates, but they are consistent in that more than half of these people are aged 80 years or older. Notwithstanding the limitations of published community studies in Portugal, including our own, their findings strongly support the urgent need for effective national policies in dementia care. These should include feasible mechanisms to estimate dementia-related needs and responses periodically in health and social systems and at regional and national levels.

\section{Acknowledgement}

A. Cardoso, J. Alves da Silva, M. Caldas de Almeida, A. Fernandes, C. Raminhos, C.P. Ferri, and M. Prince were part of the 10/66 Workgroup in Portugal. M. Prince provided helpful comments regarding parts of this paper, and without his support the 10/66 Dementia Research Group Portuguese survey would not have been possible. J. Grave helped editing the tables.

\section{Conflict of Interest Statement}

The authors have no conflict of interests to declare. 


\section{Funding Sources}

Work leading directly to this paper was not funded. The 10/66 DRG dementia prevalence study in Portugal was supported by FCT (Fundação para a Ciência e a Tecnologia; PTDC/SAUEPI/113652/2009: "Prevalence of old age neuropsychiatric disorders: contribution to mental health policy in Portugal" - P.I. M. Xavier).

\section{Author Contributions}

M.G.-P. wrote the first draft, which was thoroughly reviewed by all of the authors. M.P. supervised statistical procedures by M.J.M. All of the authors approved the final version of this paper.

\section{References}

1 Prince M, Wimo A, Guerchet M, GemmaClaire Ali M, Wu YT, Prina M, et al. World Alzheimer Report 2015: The global impact of dementia - an analysis of prevalence, incidence, cost and trends. London: Alzheimer's Disease International; 2015.

2 World Health Organization. Global action plan on the public health response to dementia 2017-2025. Geneva: WHO; 2017.

3 Nichols E, Szoeke CE, Vollset SE, Abbasi N, Abd-Allah F, Abdela J, et al.; GBD 2016 Dementia Collaborators. Global, regional, and national burden of Alzheimer's disease and other dementias, 1990-2016: a systematic analysis for the Global Burden of Disease Study 2016. Lancet Neurol. 2019 Jan;18(1):88106.

4 Alzheimer Europe. European Dementia Monitor 2017: Comparing and benchmarking national dementia strategies and policies. Luxembourg: Alzheimer Europe; 2017.

5 Gonçalves-Pereira M, Leuschner A. Portugal. In: Burns A, Robert $\mathrm{P}$, editors. Dementia care: international perspectives. Oxford: Oxford University Press; 2019. pp. 219-30.

6 Ministério da Saúde; Grupo de Trabalho na Área das Demências. Bases para a definição de políticas públicas na área das demências. Lisbon: Grupo de Trabalho na Área das Demências; 2017.

7 Gabinete do Secretário de Estado Adjunto e da Saúde. Despacho No. 5988/2018. Diário da República. 2a série. No. 116. 2018. pp. $17096-$ 101.

8 Prince M, Comas-Herrera MA, Knapp M, Guerchet M, Karagiannidou MM. World Alzheimer Report 2016: Improving healthcare for people living with dementia - Coverage, quality and costs now and in the future. London: Alzheimer's Disease International; 2016.

9 Prina AM, Mayston R, Wu YT, Prince M. A review of the 10/66 dementia research group. Soc Psychiatry Psychiatr Epidemiol. 2019 Jan;54(1):1-10.

10 Garcia C, Costa C, Guerreiro M, Leitão O, de Mendonça A, Umbelino J. Estimativa da prevalência da demência e da doença de $\mathrm{Al}$ zheimer em Portugal. Acta Med Port. 1994 Sep;7(9):487-91.

11 Alzheimer Europe. European Collaboration on Dementia (EuroCoDe): Technical report (2006-2008). Luxembourg: Alzheimer Europe; 2008 .
12 Alzheimer Europe. Portugal: 2013. The prevalence of dementia in Europe: Country comparisons - Policy in practice [Internet]. Luxembourg: Alzheimer Europe; 2013 [cited 2021 Jan 13]. Available from: http:// www.alzheimer-europe.org/Policy-inPractice2/Country-comparisons/2013The-prevalence-of-dementia-in-Europe/ Portugal.

13 Santana I, Farinha F, Freitas S, Rodrigues V, Carvalho A. [The Epidemiology of Dementia and Alzheimer Disease in Portugal: Estimations of Prevalence and TreatmentCosts]. Acta Med Port. 2015 Mar;28(2): 182-8.

14 Ferri CP, Prince M, Brayne C, Brodaty H, Fratiglioni L, Ganguli M, et al.; Alzheimer's Disease International. Global prevalence of dementia: a Delphi consensus study. Lancet. 2005 Dec;366(9503):2112-7.

15 Ramalheira C. Breves notas sobre epidemiologia das demências. In: Grupo de Estudos de Envelhecimento Cerebral e Demência, editor. 34a Reunião do Grupo de Estudos de Envelhecimento Cerebral e Demência (GEECD). Lisbon: GEECD; 2020. p. 26.

16 Nunes B, Silva RD, Cruz VT, Roriz JM, Pais J, Silva MC. Prevalence and pattern of cognitive impairment in rural and urban populations from Northern Portugal. BMC Neurol. 2010 Jun; 10(1):42

17 Gonçalves-Pereira M, Cardoso A, Verdelho A, Alves da Silva J, Caldas de Almeida M, Fernandes A, et al. The prevalence of dementia in a Portuguese community sample: a 10/66 Dementia Research Group study. BMC Geriatr. 2017 Nov;17(1):261.

18 Ruano L, Araújo N, Branco M, Barreto R, Moreira S, Pais R, et al. Prevalence and causes of cognitive impairment and dementia in a population-based cohort from Northern Portugal. Am J Alzheimers Dis Other Demen. 2019 Feb;34(1):49-56.

19 Alzheimer Europe. Dementia in Europe: Yearbook 2019 - Estimating the prevalence of dementia in Europe. Luxembourg: Alzheimer Europe; 2020.

20 American Psychiatric Association. Diagnostic and statistical manual of mental disorders. 4th ed. Washington: APA; 1994.

21 Gonçalves-Pereira M, Cardoso A, Verdelho A, Alves da Silva J, Caldas de Almeida M, Fernandes A, et al. Implementação em Portugal de um estudo de prevalência da demência e da depressão geriátrica: a metodologia do 10/66 Dementia Research Group [Implementing a prevalence study of dementia and geriatric depression in Portugal: the 10/66 DRG methodology]. Rev Port Saude Publica. 2016 May;34(2):134-43.

22 Prince M, Ferri CP, Acosta D, Albanese E, Arizaga R, Dewey M, et al. The protocols for the 10/66 dementia research group population-based research programme. BMC Public Health. 2007 Jul;7(1):165.

23 Prince M, Jackson J. World Alzheimer Report 2009. London: Alzheimer's Disease International; 2009.

24 Bacigalupo I, Mayer F, Lacorte E, Di Pucchio A, Marzolini F, Canevelli M, et al. A systematic review and meta-analysis on the prevalence of dementia in Europe: estimates from the highest-quality studies adopting the DSM IV diagnostic criteria. J Alzheimers Dis. 2018;66(4):1471-81.

25 Minett T, Stephan B, Brayne C. Epidemiology of old age psychiatry: An overview of concepts and main studies. In: Dening T, Thomas A, editors. Oxford textbook of old age psychiatry. 2nd ed. Oxford: Oxford University Press; 2013. pp. 57-85.

26 Prince M. Commentary: two-phase surveys. A death is announced; no flowers please [Commentary]. Int J Epidemiol. 2003 Dec;32(6):1078-80.

27 da Silva J, Gonçalves-Pereira M, Xavier M, Mukaetova-Ladinska EB. Affective disorders and risk of developing dementia: systematic review. Br J Psychiatry. 2013 Mar;202(3):17786.

28 Livingston G, Sommerlad A, Orgeta V, Costafreda SG, Huntley J, Ames D, et al. Dementia prevention, intervention, and care. Lancet. 2017 Dec;390(10113):2673-734.

29 Moura AR, Gonçalves-Pereira M. Letter to the Editor Regarding the Article "Geriatric Assessment of the Portuguese Population Aged 65 and Over Living in the Community: The PEN-3S study". On Clinically Significant Depression and Validity of Cut-off Points. Acta Med Port. 2020;33(11):784-5.

30 Copeland JR, Prince M, Wilson KC, Dewey ME, Payne J, Gurland B. The geriatric mental state examination in the 21 st century. Int J Geriatr Psychiatry. 2002 Aug;17(8):72932. 
31 Gonçalves-Pereira M, Prina AM, Cardoso AM, da Silva JA, Prince M, Xavier M; 10/66 Workgroup in Portugal. The prevalence of late-life depression in a Portuguese community sample: A 10/66 Dementia Research Group study. J Affect Disord. 2019 Mar;246:674-81.

32 Brayne CE, Barnes LE, Breteler MM, Brooks RL, Dufouil C, Fox C, et al. Dementia research fit for the planet: reflections on population studies of dementia for researchers and policy makers alike. Neuroepidemiology. 2020;54 2:157-70.

33 Niu H, Álvarez-Álvarez I, Guillén-Grima F, Aguinaga-Ontoso I. Prevalence and incidence of Alzheimer's disease in Europe: A meta-analysis. Neurologia. 2017 Oct;32(8):523-32.

34 Launer LJ. Counting dementia: there is no one "best" way. Alzheimers Dement. 2011 Jan;7(1):10-4.

35 Censos INE. 2011: Resultados definitivos Portugal. Lisbon: Instituto Nacional de Estatística; 2012.

36 Instituto Nacional de Estatistica. Estimativas da população residente: Portugal - 2019. Lisbon: Instituto Nacional de Estatística; 2020.

37 OECD. Health at alance 2017. Paris: OECD; 2017.

38 Prince M, Acosta D, Chiu H, Scazufca M, Varghese M; 10/66 Dementia Research Group. Dementia diagnosis in developing countries: a cross-cultural validation study. Lancet. 2003 Mar;361(9361):909-17.

39 Llibre Rodriguez JJ, Ferri CP, Acosta D, Guerra M, Huang Y, Jacob KS, et al.; 10/66 Dementia Research Group. Prevalence of dementia in Latin America, India, and China: a population-based cross-sectional survey. Lancet. 2008 Aug;372(9637):464-74.

40 Alzheimer Europe. Dementia in Europe Yearbook 2017: Standards for residential care facilities in Europe. Luxembourg: Alzheimer Europe; 2018. pp. 1-65.

41 Joël ME, Dufour-Kippelen S, Samitca S. The long-term care system for the elderly in Portugal. Brussels: European Network of Economic Policy Research Institutes; 2010.

42 Ministério do Trabalho Solidariedade e Segurança Social Portugal. Carta Social: Rede de Serviços e Equipamentos [Internet]. Lisbon: Gabinete de Estratégia e Planeamento do Ministério do Trabalho Solidariedade e Segurança Social;2020. [cited 2021 Jan 13]. Available from: http://www.gep.mtsss.gov.pt/carta-social.

43 Ministério da Saúde Portugal. ACSS: Relatório de monitorização da Rede Nacional de Cuidados Continuados e Integrados (RNCCI) 2019. Lisbon: Agência de Acreditação dos Serviços de Saúde; 2019.

44 Alzheimer Europe. Portugal: National dementia strategies - Policy in practice [Internet]. Luxembourg: Alzheimer Europe; 2009 [cited 2021 Jan 13]. Available from http:// www.alzheimer-europe.org/Policy-in-Practice 2/National-Dementia-Strategies/ Portugal?\#fragment1.
45 Caldas de Almeida M. Projecto VIDAS: Valorização e Inovação em Demências. Lisbon: União das Misericórdias Portuguesas; 2015.

46 Paúl et al. apud Carvalho A, Mateus P, Xavier M. Portugal: Saúde mental em números 2015: Programa Nacional para a Saúde Mental. Lisbon: Direção-Geral da Saúde; 2016.

47 Amaro F. Problemas e necessidades psicossociais de pessoas idosas em Centros de Dia e ERPI, em relação com as demências: relatório final Dez 2016. Lisbon: Centro de Administração e Políticas Públicas; 2017.

48 Alzheimer Portugal. Projeto Cuidar Melhor: Apoio a cuidadores de pessoas com demência [Internet]. Lisbon: Alzheimer Portugal; 2020. [cited 2021 Jan 13]. Available from: http:// cuidarmelhor.org/.

$49 \mathrm{Wu}$ YT, Beiser AS, Breteler MM, Fratiglioni L, Helmer C, Hendrie HC, et al. The changing prevalence and incidence of dementia over time - current evidence. Nat Rev Neurol. 2017 Jun;13(6):327-39.

50 Prince M, Ali GC, Guerchet M, Prina AM, Albanese E, Wu YT. Recent global trends in the prevalence and incidence of dementia, and survival with dementia. Alzheimers Res Ther. 2016 Jul;8(1):23.

51 Stephan BC, Birdi R, Tang EY, Cosco TD, Donini LM, Licher S, et al. Secular trends in dementia prevalence and incidence worldwide: a systematic review. J Alzheimers Dis. 2018;66(2):653-80.

52 World Health Organization. Dementia: A public health priority [Internet]. Geneva: WHO; 2017 [cited 2017 Oct 31]. Available from: http://www.who.int/mental_health/ neurology/dementia/en/.

53 United Nations. World population ageing 2015: Highlights. Washington: United Nations; 2015.

54 Broda A, Bieber A, Meyer G, Hopper L, Joyce $\mathrm{R}$, Irving K, et al.; ActifCare Consortium. Perspectives of policy and political decision makers on access to formal dementia care: expert interviews in eight European countries. BMC Health Serv Res. 2017 Aug;17(1):518.

55 Alzheimer's Disease International. From plan to impact: Progress towards targets of the global action plan on dementia. London: Alzheimer's Disease International; 2018.

56 Lobo A, Lobo E, De-la-Cámara C. Dementia care in high-income countries. Curr Opin Psychiatry. 2019 Sep;32(5):465-70.

57 OECD. Policy brief: Renewing priority for dementia - where do we stand? Paris: OECD; 2018.

58 Oliveira D, Jun Otuyama L, Mabunda D, Mandlate F, Gonçalves-Pereira M, Xavier M, et al. Reducing the number of people with dementia through primary prevention in Mozambique, Brazil, and Portugal: an analysis of population-based data. J Alzheimers Dis. 2019;70(s1):S283-91.
59 World Health Organization. Guidelines on Integrated Care for Older People (ICOPE). Geneva: World Health Organization; 2017.

60 Prince M, Acosta D, Guerra M, Huang Y, Jacob KS, Jimenez-Velazquez I, et al. Intrinsic capacity as a framework for Integrated Care for Older People (ICOPE): insights from the 10/66 Dementia Research Group cohort studies in Latin America, India and China. medRxiv. 2019;19006403.

61 Balsinha C, Gonçalves-Pereira M, Iliffe S, Freitas JA, Grave J. Health-care delivery for older people with dementia in primary care. In: Ivbijaro GO, Mendonça-Lima C, editors. Primary care mental health in older people. Cham: Springer; 2019. pp. 311-29.

62 World Health Organization. Towards a dementia plan: A WHO guide. Geneva: WHO; 2018.

63 Shah H, Albanese E, Duggan C, Rudan I, Langa KM, Carrillo MC, et al. Research priorities to reduce the global burden of dementia by 2025. Lancet Neurol. 2016 Nov;15(12):128594.

64 Fernandes L, Gonçalves-Pereira M, Leuschner A, Martins S, Sobral M, Azevedo LF, et al. Validation study of the Camberwell Assessment of Need for the Elderly (CANE) in Portugal. Int Psychogeriatr. 2009 Feb;21(1):94-102.

65 Gonçalves-Pereira M, Marques MJ, Balsinha C, Fernandes A, Machado AS, Verdelho A, et al. [Needs for Care and Service Use in Dementia: Baseline Assessment of Portuguese Participants in the Actifcare Cohort Study]. Acta Med Port. 2019 May;32(5):355-67.

66 Jones B, Gage H, Bakker C, Barrios H, Boucault S, Mayer J, et al.; RHAPSODY Study Group. Availability of information on young onset dementia for patients and carers in six European countries. Patient Educ Couns. 2018 Jan;101(1):159-65.

67 Freitas S, Nogueira J, Gerardo B, Alves L. Estudo epidemiológico: Incidência do declínio cognitivo em Portugal. In: Grupo de Estudos de Envelhecimento Cerebral e Demência, editor. 34a Reunião do Grupo de Estudos de Envelhecimento Cerebral e Demência (GEECD). Lisbon: GEECD; 2020. p. 20

68 Brandão D, Freitas A, Paúl C, Ribeiro O. Psychiatric disorders as main discharge diagnosis by the Portuguese oldest old from 2000 to 2014: exploring national acute inpatient admissions. Int Psychogeriatr. 2018 May;30(5):685-94.

69 Bernardes C, Massano J, Freitas A. Hospital admissions 2000-2014: A retrospective analysis of 288096 events in patients with dementia. Arch Gerontol Geriatr. 2018 Jul Aug;77:150-7.

70 Passos J, Fonte A, Dias CC, Fernandes L. The needs of older people with mental health problems in a Portuguese psychiatric setting. Int Psychogeriatr. 2017 May;29(5):845-53.
Counts of People with Dementia in

Portugal: A Discussion of Estimates
Port J Public Health 2021;39:58-67 DOI: $10.1159 / 000516503$ 